\title{
Angiography-derived index of microcirculatory resistance as a novel, pressure-wire-free tool to assess coronary microcirculation in ST elevation myocardial infarction
}

\author{
Giovanni Luigi De Maria ${ }^{1} \cdot$ Roberto Scarsini $^{1} \cdot$ Mayooran Shanmuganathan ${ }^{1,2} \cdot$ Rafail A. Kotronias $^{1} \cdot$ \\ Dimitrios Terentes-Printzios ${ }^{1}$ - Alessandra Borlotti ${ }^{1}$. Jeremy P. Langrish ${ }^{1}$. Andrew J. Lucking ${ }^{1} \cdot$ Robin P. Choudhury $^{1}$. \\ Rajesh Kharbanda ${ }^{1}$ Vanessa M. Ferreira ${ }^{1,2}$. Oxford Acute Myocardial Infarction (OXAMI) Study Investigators . \\ Keith M. Channon ${ }^{1} \cdot$ Hector M. Garcia-Garcia ${ }^{3}$. Adrian P. Banning ${ }^{1}$
}

Received: 20 January 2020 / Accepted: 28 March 2020 / Published online: 14 May 2020

(c) The Author(s) 2020

\begin{abstract}
Immediate assessment of coronary microcirculation during treatment of ST elevation myocardial infarction (STEMI) may facilitate patient stratification for targeted treatment algorithms. Use of pressure-wire to measure the index of microcirculatory resistance (IMR) is possible but has inevitable practical restrictions. We aimed to develop and validate angiographyderived index of microcirculatory resistance $\left(\mathrm{IMR}_{\text {angio }}\right)$ as a novel and pressure-wire-free index to facilitate assessment of the coronary microcirculation. 45 STEMI patients treated with primary percutaneous coronary intervention (pPCI) were enrolled. Immediately before stenting and at completion of pPCI, IMR was measured within the infarct related artery (IRA). At the same time points, 2 angiographic views were acquired during hyperaemia to measure quantitative flow ratio (QFR) from which $\mathrm{IMR}_{\text {angio }}$ was derived. In a subset of 15 patients both IMR and IMR $\mathrm{angio}_{\text {wo }}$ were also measured in the non-IRA. Patients underwent cardiovascular magnetic resonance imaging (CMR) at $48 \mathrm{~h}$ for assessment of microvascular obstruction (MVO). IMR angio and IMR were significantly correlated $(\rho: 0.85, \mathrm{p}<0.001)$. Both IMR and $\mathrm{IMR}_{\text {angio }}$ were higher in the IRA rather than in the non-IRA ( $\mathrm{p}=0.01$ and $\mathrm{p}=0.006$, respectively) and were higher in patients with evidence of clinically significant MVO ( $>1.55 \%$ of left ventricular mass) $(\mathrm{p}=0.03$ and $\mathrm{p}=0.005$, respectively). Post-pPCI IMR angio presented and area under the curve (AUC) of 0.96 (CI95\% 0.92-1.00, $\mathrm{p}<0.001)$ for prediction of post-pPCI IMR $>40 \mathrm{U}$ and of 0.81 $(\mathrm{CI} 95 \% 0.65-0.97, \mathrm{p}<0.001)$ for $\mathrm{MVO}>1.55 \%$. IMR $\mathrm{Ingio}_{\text {is }}$ is a promising tool for the assessment of coronary microcirculation. Assessment of IMR without the use of a pressure-wire may enable more rapid, convenient and cost-effective assessment of coronary microvascular function.
\end{abstract}

Keywords Index of microcirculatory resistance $\cdot$ Microvascular obstruction $\cdot$ Quantitative flow ratio $\cdot$ Microvascular dysfunction $\cdot$ STEMI

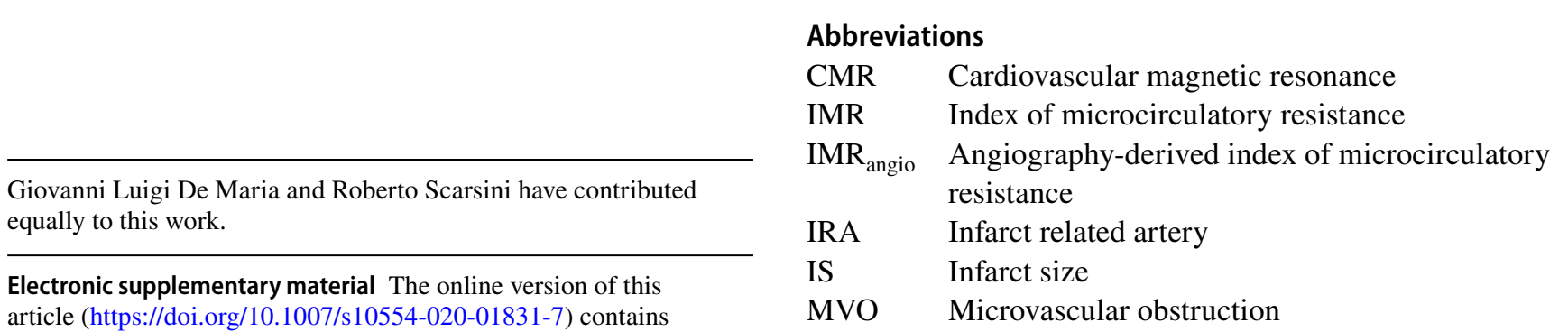

Adrian P. Banning

adrian.banning@ouh.nhs.uk

Oxford Heart Centre, NIHR Biomedical Research Centre, Oxford University Hospitals, Headley Way, Oxford OX39DU, UK
Oxford Centre for Clinical Magnetic Resonance Research (OCMR), University of Oxford, Oxford, UK

3 MedStar Washington Hospital Center, Washington, DC, USA 


$\begin{array}{ll}\mathrm{Pa} & \text { Aortic pressure } \\ \mathrm{Pd} & \text { Distal pressure } \\ \text { QFR } & \text { Quantitative flow ratio } \\ \text { STEMI } & \text { ST elevation myocardial infarction }\end{array}$

\section{Introduction}

Coronary microvascular injury remains an important determinant of poor prognosis and an unsolved challenge in the management of patients with ST elevation myocardial infarction (STEMI). The index of microcirculatory resistance (IMR) has been proposed to provide information about the status of coronary microvasculature and it is based on the combined application of thermodilution technique and of coronary pressure-wire [1]. It has been validated against cardiovascular magnetic resonance imaging (CMR) [2] and against major clinical outcomes. Measured at the completion of the procedure, a post-pPCI IMR $\geq 40 \mathrm{U}$ is associated with a higher rate of mortality and readmission for heart failure in STEMI patients [3]. Moreover, IMR has been showed to provide information about the status of the microvasculature before stenting [4], and either alone or in combination with other clinical and anatomical parameters it can provide an immediate indicator of patients at high risk of suboptimal reperfusion $[5,6]$.

Despite encouraging preliminary results of studies showing the potential efficacy of IMR-guidance in triaging novel therapies in STEMI [7], IMR is still perceived as a research tool and its application within clinical practice remains extremely limited. Probable reasons for a lack of clinical penetration include the additional procedural time /complexity, increased procedural cost and the potential challenge of pressure wire manipulation in the infarct related artery (IRA) in STEMI patients.

Quantitative flow ratio (QFR) is a novel angiographybased index derived from application of computational flow dynamics to three-dimensional modelling of the coronary artery [8]. QFR has been shown to have a good correlation with invasive fractional flow reserve (FFR) and it appears to be superior to angiography in assessing the ischemic potential of angiographically intermediate coronary stenosis [9]. QFR does not rely on pressure-wire use, but it remains an index for characterization of coronary epicardial segment and does not provide direct assessment of coronary microcirculation.

By measuring QFR in the IRA, we aimed to derive and validate a novel index, the angiography-derived index of microcirculatory resistance $\left(\mathrm{IMR}_{\text {angio }}\right)$, to provide a pressure-wire-free alternative to IMR for the assessment of coronary microvasculature.

\section{Methods}

Patients with STEMI admitted to the Oxford Heart Centre for pPCI between September 2018 and August 2019 were prospectively considered for enrolment in the OxAMI (Oxford Acute Myocardial Infarction) study. Details about OxAMI study have been previously described [10]. The OxAMI study protocol was approved by the local ethics committee (REC number 10/H0408/24) and conducted in accordance with the Declaration of Helsinki.

STEMI was defined as the occurrence of ongoing chest pain for at least $30 \mathrm{~min}$ associated with ST-segment elevation $>2 \mathrm{~mm}$ in at least two contiguous leads. Enrolled patients were excluded for IMR angio $_{\text {and IMR assessment }}$ in case of haemodynamic instability, evidence of angiographic left main disease, anticipated plain old balloon angioplasty without stent implantation or unsuitability for CMR assessment.

Figure 1 summarizes the study-methods as described in detail within the next sections.

\section{Index of microcirculatory resistance measurement}

IMR was measured using thermodilution technique on the CoroFlow system (Coroventis, Uppsala Sweden) as previously described, immediately before stenting and at completion of pPCI [4]. Briefly, a standard pressure wire (PressureWire X, Abbott, Santa Clara, CA) was calibrated, equalized and advanced towards the distal third of the IRA. After intracoronary injection of $250 \mu \mathrm{g}$ isosorbide dinitrate, mean aortic pressure $(\mathrm{Pa})$, mean distal pressure (Pd) and mean transit time (tTmean) were measured both at baseline and at hyperaemia, achieved with intravenous infusion of adenosine at a rate of $140 \mu \mathrm{g} / \mathrm{kg} / \mathrm{min}$. Mean transit time was calculated as the average of three transit time measurements during three separate injections of $3 \mathrm{ml}$ of room temperature $0.9 \%$ saline solution. IMR was then calculated as follows:

$I M R=P d_{(\text {hyperaemia })} \times \operatorname{tTmean}_{(\text {hyperaemia })}$

when assessed before stenting, IMR was measured either according to the above formula and also corrected 


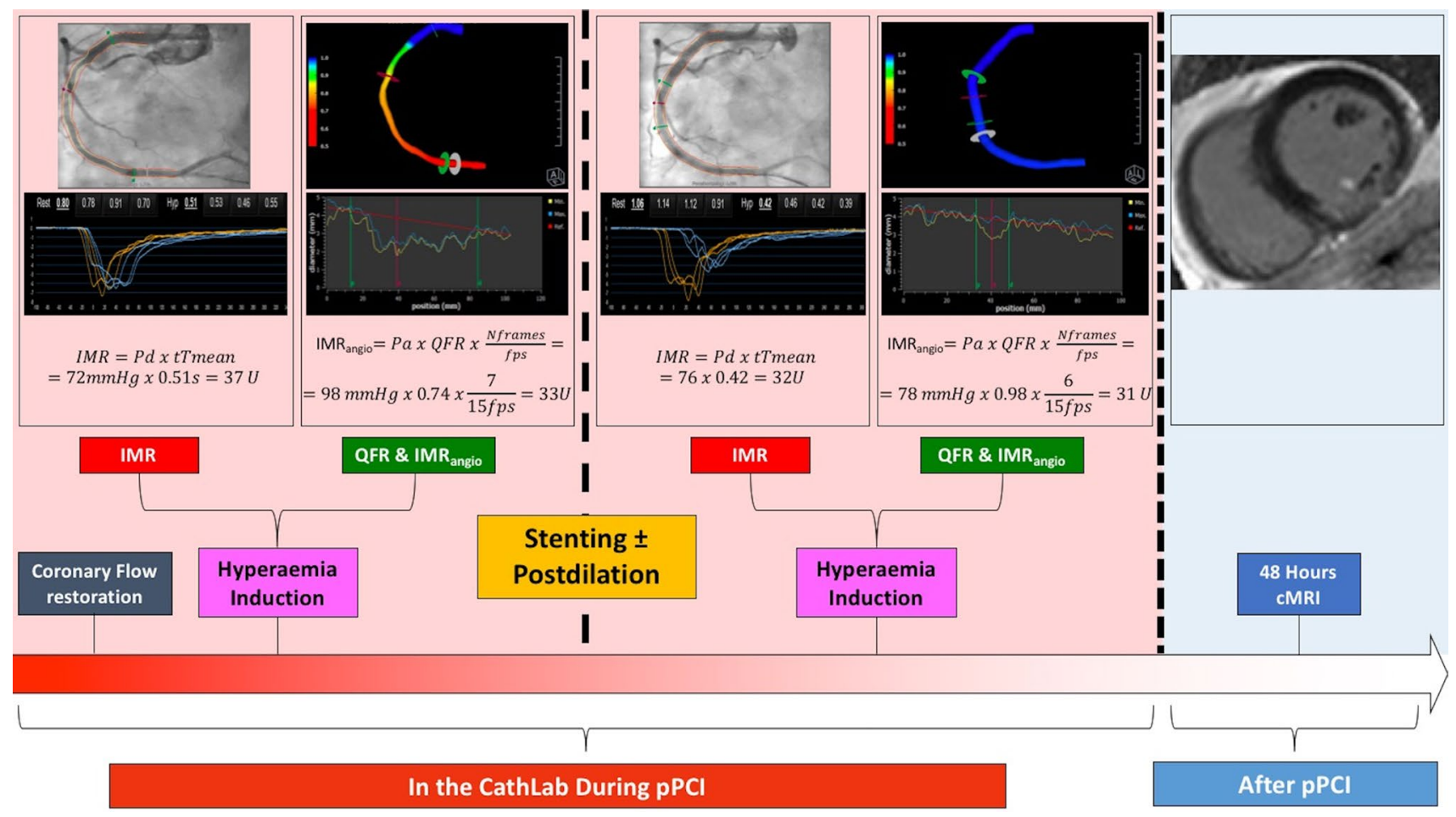

Fig. 1 Study methods flow chart

for coronary wedge pressure, to account for residual collateral flow:

$$
\begin{aligned}
I M R= & \mathrm{Pa}(\text { hyperaemia }) \times \mathrm{t} \text { Tmean }(\text { hyperaemia }) \\
& \times \frac{\text { Pd(hyperaemia })- \text { Pcorwedge }}{\text { Pa(hyperaemia })- \text { Pcorwedge }}
\end{aligned}
$$

Coronary wedge pressure was measured by the pressure sensor of the pressure-wire during prolonged angioplastyballoon inflation.

In a subset of patients, IMR was measured also in one of the two non-IRAs. The selection of which non-IRA to assess was left to operator's discretion.

\section{Quantitative flow ratio measurement}

At the same time points when IMR was measured, and only when measurement of IMR was completed, angiographic images were acquired at 15 frame/second with manual injection of contrast dye during maximal hyperaemia, using a monoplane radiographic system (Siemens Healthcare, Germany). Pre-specified projections were agreed with the radiographer to guarantee views at least $25^{\circ}$ apart.

Three-dimensional quantitative coronary angiography (3D-QCA) and then QFR were measured off-line using QAngio ${ }$ XA 3D software (Medis, Leiden, the Netherlands) by two independent operators (RS, MS) blinded to clinical,
IMR and CMR data. Contrast-flow QFR (cQFR) and fixedflow QFR (fQFR) were provided. Cases of disagreement were resolved by consensus.

Since IMR is measured during maximal hyperaemia, we elected to assess $\mathrm{IMR}_{\text {angio }}$ under hyperaemic conditions, as well. For this reason, QFR was assessed using the angiographic views taken at peak hyperaemia during adenosine infusion. Pressure-wire was left in place during angiographic acquisition to allow calculation of QFR exactly at the site of the distal pressure/temperature transducer.

As per IMR, in a subset of patients, QFR was measured also in one of the two non-IRAs.

\section{Angiography-derived index of microcirculatory resistance}

$\mathrm{IMR}_{\text {angio }}$ was derived starting from the formula for calculation of IMR.

$\mathrm{IMR}=\operatorname{Pd}_{(\text {hyperaemia) }} \times \mathrm{tTmean}_{\text {(hyperaemia) }}$

where $\mathrm{Pd}_{(\text {hyperaemia) }}$ is distal pressure at hyperaemia and tTmean $_{\text {(hyperaemia) }}$ is mean transit time at hyperaemia. By multiplying and dividing by hyperaemic aortic pressure $\left(\mathrm{Pa}_{\text {(hyperaemia) }}\right)$, the formula becomes: 
$I M R=P a($ hyperaemia $) \times \frac{P d(\text { hyperaemia })}{P a(\text { hyperaemia })} \times t$ Tmean $($ hyperaemia $)$

Since QFR is a surrogate of Pd(hyperaemia)/ $\mathrm{Pa}$ (hyperaemia) ratio, $\left(\mathrm{QFR} \sim \frac{\text { Pd(hyperaemia })}{\text { Pa(hyperaemia })}\right), \mathrm{QFR}$ can be used to replace $\frac{P d \text { (hyperaemia })}{P a \text { (hyperaemia })}$ in the formula. Similarly, tTmean $_{\text {(hyperaemia) }}$ can be expressed as the ratio between the number of frames (Nframes) for contrast dye to travel, during hyperaemia, from the guiding catheter to a distal reference (corresponding to the position of the distal marker of the pressure wire) divided by the acquisition rate (fps).

In this way the formula becomes:

$I M R$ angio $=P a($ hyperaemia $) \times Q F R \times \frac{\text { Nframes }(\text { hyperaemia })}{f p s}$

being fps set at 15 frame/second for QFR measurement.

$\mathrm{IMR}_{\text {angio }}$ was derived in the IRA at the same time points when IMR was measured, and in the non-IRAs where IMR assessment was performed per protocol.

\section{Cardiovascular magnetic resonance imaging}

CMR scans were performed at $48 \mathrm{~h}$ after pPCI using a $3.0 \mathrm{~T}$ scanner (either MAGNETOM TIMTrio or MAGNETOM Verio, Siemens Healthcare, Germany). Sequence acquisition was performed as previously described [11].

Microvascular obstruction (MVO) was defined as hypointense area within the hyperenhancement region on the late gadolinium enhancement images and was manually contoured [11]. We considered an MVO $>1.55 \%$ of left ventricle mass as prognostically significant based on de Waha et al. [12].

\section{Statistical analysis}

After verifying normal distribution by Shapiro-Wilk's test, variables were expressed as mean and $( \pm)$ standard deviation (SD) or as median accompanied by interquartile range (IQR), as appropriate. Frequencies were compared using Chi square test or Fisher's exact test, as appropriate. Continuous variables were compared using T test or analysis of variance (ANOVA) with Scheffe's post-hoc comparisons, as appropriate. Non-normally distributed continuous variables were compared using Mann-Whitney's test or Kruskall Wallis' test, as appropriate. $\mathrm{T}$ test or Wilcoxon test were used as appropriate for paired samples. Correlations between variables were expressed using Pearson r or Spearman rho coefficients as appropriate.

Inter-rater reliability was assessed by interclass coefficient (ICC) and corresponding 95\% confidence interval.

The concordance between IMR angio $_{\text {and IMR was assessed }}$ by Bland-Altman plot and the diagnostic efficiency of $\mathrm{IMR}_{\text {angio }}$ in predicting IMR $\geq 40 \mathrm{U}$ and $\mathrm{MVO}>1.55 \%$ was assessed by the area under the receiver-operating characteristic curve. Youden index analysis was used to identify best cut-off of $\mathrm{IMR}_{\text {angio }}$ for prediction of post-pPCI IMR $\geq 40 \mathrm{U}$.

Statistical analysis was performed using SPSS 24.0 (SPSS, Inc Chicago, Illinois) and a p value $<0.05$ was considered statistically significant.

\section{Results}

\section{Clinical and procedural characteristics}

A total of 45 STEMI patients were included in the current analysis (Fig. 2). Clinical and procedural characteristics are presented for the whole cohort (Table 1) and stratified


Table 1 and 2). The cut-off of $40 \mathrm{U}$ for $\mathrm{IMR}_{\text {angio }}$ was derived from ROC analysis (see "Correlations between IMR and $\mathrm{IMR}_{\text {angio }}$ " section).

\section{Correlations between IMR and IMR angio $_{\text {}}$}

Satisfactory inter-rater reliability was detected for QFR (ICC 0.83 (CI95\% 0.61-0.93), F=6.37, p < 0.001) and $\mathrm{IMR}_{\text {angio }}$ (ICC 0.93 (CI95\% 0.84-0.97), F=14.02, p <0.001).
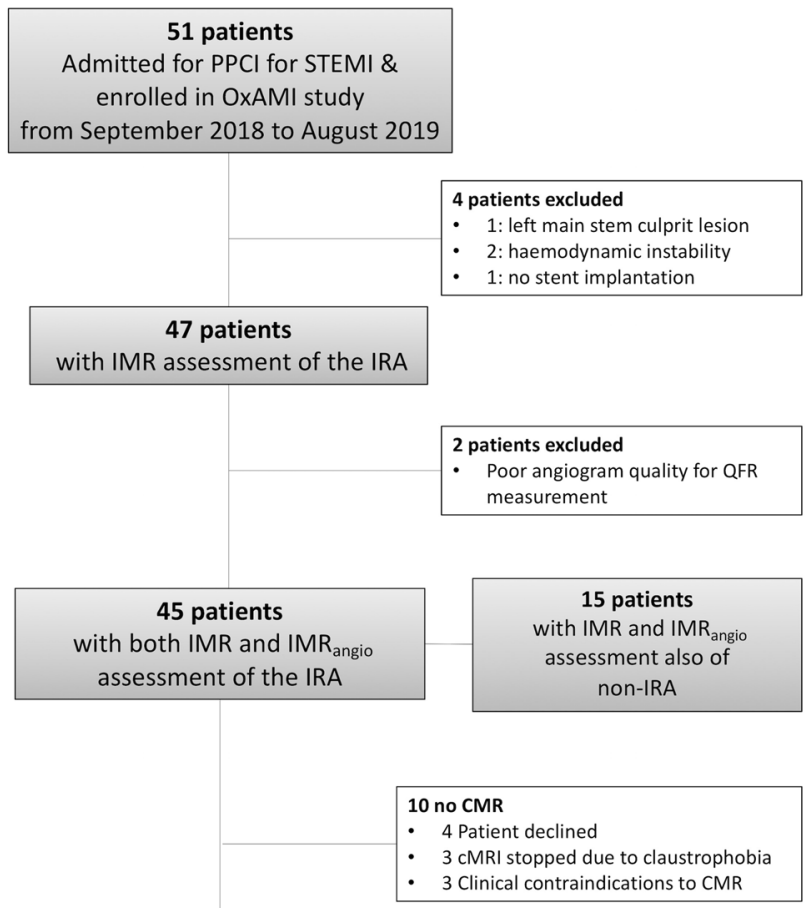

35 patients

with both IMR and IMR angio assessment of the IRA and $48 \mathrm{~h}$ CMR

Fig. 2 Patients flow chart 
Table 1 Overall clinical, angiographic and procedural characteristics

\begin{tabular}{|c|c|}
\hline Clinical data & $\mathrm{n}=45$ \\
\hline Age, years & $61.5(54.7-71.0)$ \\
\hline Male $(\%)$ & $35(77.8)$ \\
\hline Hypertension (\%) & $28(62.2)$ \\
\hline Hypercholesterolemia (\%) & $19(42.2)$ \\
\hline Active Smoker (\%) & $26(57.0)$ \\
\hline Diabetes (\%) & $8(17.7)$ \\
\hline Family history of CAD (\%) & $14(31.1)$ \\
\hline Ischemic time, minutes $(I Q R)$ & $196.0(127.5-425.5)$ \\
\hline \multicolumn{2}{|l|}{ Culprit vessel } \\
\hline$L A D(\%)$ & $22(48.8)$ \\
\hline$L C x(\%)$ & $6(13.3)$ \\
\hline$R C A(\%)$ & $17(37.9)$ \\
\hline \multicolumn{2}{|l|}{ TIMI flow at presentation } \\
\hline $0(\%)$ & $26(57.8)$ \\
\hline $1(\%)$ & $4(8.9)$ \\
\hline $2(\%)$ & $10(22.2)$ \\
\hline $3(\%)$ & $5(11.1)$ \\
\hline \multicolumn{2}{|l|}{ Periprocedural medication } \\
\hline Aspirin (\%) & $45(100.0)$ \\
\hline Clopidogrel (\%) & $45(100.0)$ \\
\hline Heparin $(\%)$ & $21(46.7)$ \\
\hline Bivalirudin (\%) & $24(53.3)$ \\
\hline GPIIbIIIa inhibitors (\%) & $3(6.6)$ \\
\hline \multicolumn{2}{|c|}{ Angiographic and procedural data } \\
\hline Thrombus aspiration (\%) & $10(22.2)$ \\
\hline Predilation (\%) & $45(100)$ \\
\hline Total stent length, mm & $24.0(20.0-38.0)$ \\
\hline Stent diameter, mm & $3.5(3.0-4.0$ \\
\hline Postdilation (\%) & $38(84.4)$ \\
\hline \multicolumn{2}{|l|}{ Final TIMI flow } \\
\hline $0(\%)$ & $0(0.0)$ \\
\hline $1(\%)$ & $2(4.4)$ \\
\hline $2(\%)$ & $3(6.7)$ \\
\hline $3(\%)$ & $40(88.9)$ \\
\hline Thrombus score $\geq 4$ & $23(51.1)$ \\
\hline \multicolumn{2}{|l|}{ Haemodynamics } \\
\hline \multicolumn{2}{|l|}{ Pre-stenting } \\
\hline Hyperemic $\mathrm{Pd} / \mathrm{Pa}$ & $0.75(0.61-0.85)$ \\
\hline CFR & $1.27(1.11-1.67)$ \\
\hline IMR & $48.6(25.5-60.3)$ \\
\hline $\mathrm{cQFR}$ & $0.76(0.64-0.86)$ \\
\hline fQFR & $0.74(0.57-0.84)$ \\
\hline $\mathrm{IMR}_{\text {angio }}$ & $37.3(23.7-50.2)$ \\
\hline \multicolumn{2}{|l|}{ Post-pPCI } \\
\hline Hyperemic $\mathrm{Pd} / \mathrm{Pa}$ & $0.95(0.90-0.98)$ \\
\hline CFR & $1.81(1.51-2.26)$ \\
\hline IMR & $30.9(16.5-52.9)$ \\
\hline $\mathrm{cQFR}$ & $0.95(0.88-0.98)$ \\
\hline fQFR & $0.95(0.89-0.99)$ \\
\hline $\mathrm{IMR}_{\text {angio }}$ & $30.0(19.3-43.9)$ \\
\hline
\end{tabular}

Good correlation was observed between FFR and QFR (Supplementary Fig. 1).

IMR and $\mathrm{IMR}_{\text {angio }}$ were significantly correlated in the overall sample of 92 lesions (37 IRA pre-pPCI, 40 IRA post-pPCI and 15 non IRA) $(\rho=0.85, p<0.001)$. Correlation between the two variables was maintained when analysis was restricted to only IRA pre-pPCI $(\rho=0.73, p<0.001)$, IRA post-pPCI $(\rho=0.88, p<0.001)$ and to the non-IRA $(\rho=0.64, p=0.009)$ (Fig. 3).

Pre-pPCI IMR angio $_{\text {was }}$ also significantly correlated with pre-pPCI IMR corrected by coronary wedge pressure $(\rho=0.80, p=0.03)$.

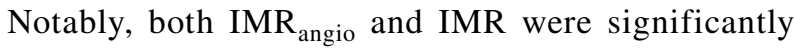
lower in the non-IRA compared to IRA $\left(\mathrm{IMR}_{\text {angio }}=17.8 \mathrm{U}\right.$ (12.2-29.9) vs 30.0U (20.5-44.3), $\mathrm{p}=0.006$; IMR $=19.0 \mathrm{U}$ $(12.5-27.5)$ vs $31.0(16.8-55.2), \mathrm{p}=0.01)$ (Supplementary Fig. 2).

ROC curve analysis showed an excellent diagnostic performance of $\mathrm{IMR}_{\text {angio }}$ in predicting an IMR $\geq 40 \mathrm{U}$ $(\mathrm{AUC}=0.96$ (CI95\% 0.92-1.00, p <0.001; Fig. 3e). The optimal cut-off of IMR angio $_{\text {for prediction of IMR } \geq 40 \mathrm{U} \text { was }}$ 40U (sensitivity $83.0 \%$, specificity $100 \%$, negative predictive value $90.2 \%$, positive predictive value $96.8 \%$, diagnostic accuracy $92.4 \%$ ).

Bland Altman analysis further confirmed concordance between $\mathrm{IMR}_{\text {angio }}$ within the whole sample and across subgroups (IRA pre-pPCI, IRA post-pPCI and non IRA) (Fig. 4). Only seven discordant cases were identified when a threshold of $40 \mathrm{U}$ was applied for both IMR and IMR angio . Binary logistic regression analysis could not identify any clinical or procedural factors associated with IMR/IMR ${ }_{\text {angio }}$ discordance (Supplementary Table 3).

\section{Variation of IMR and IMR angio $_{\text {after }} \mathrm{pPCI}$}

Assessment of both IMR $\mathrm{Ingio}_{\text {and }}$ anR before and after stenting was available in 33 out of 45 patients. Both $\mathrm{IMR}_{\text {angio }}$ and IMR decreased significantly after stenting in the IRA ( $\mathrm{IMR}_{\text {angio }}$ from $40.7 \mathrm{U}(25.0-50.2)$ to 28.2 (20.2-41.7), $\mathrm{p}=0.048$; IMR from 48.6U (25.5-64.4) to 31.0 (16.9-51.7), $\mathrm{p}=0.048$ ) (Fig. 5). Variation in $\mathrm{IMR}_{\text {angio }}$ mirrored the one observed for IMR when patients were labelled as good or partial/poor responders to stenting, based on post-pPCI IMR $\geq$ or $<40 \mathrm{U}$, respectively. In good responders IMR $\mathrm{IMgio}_{\text {an }}$ went from $32.4 \mathrm{U}(23.7-48.2)$ to $21.3 \mathrm{U}$ $(14.9-31.7)(\mathrm{p}=0.002)$ and IMR from 41.9U $(22.6-58.9)$ to $20.3 \mathrm{U}(15.0-28.0)(\mathrm{p}=0.001)$. In partial/poor responders $\mathrm{IMR}_{\text {angio }}$ went from 44.3U (25.0-57.6) to $44.8 \mathrm{U}(41.2-64.3)$ $(\mathrm{p}=0.18)$ and IMR from $57.5 \mathrm{U}(34.4-102.8)$ to $66.2 \mathrm{U}$ (43.1-105.9) $(\mathrm{p}=0.21)$. Using the threshold of 40U, postpPCI IMR categorized $63.6 \%$ of patients as good responders, whilst post-pPCI IMR angio $_{\text {categorized }} 69.7 \%$ of patients as good responders $(\mathrm{p}=0.69) . \mathrm{IMR}_{\text {angio }}$ presented a $3 \%$ 
Table 2 CMR at $48 \mathrm{~h}$ assessment stratified according to post-pPCI IMR angio $\geq 40 \mathrm{U}$
Fig. $3 \mathrm{IMR}_{\text {angio }}$ and IMR correlations in acute STEMI patients. Scatter plots summarise significant correlations between IMR angio and IMR in the overall cohort of 92 lesions assessed (a) and then split into IRA before stent implant (b), IRA after stent implant (c) and non-IRA (d). Dotted lines represent $95 \%$ Confidence interval. Panel E reports ROC curve analysis for $\mathrm{IMR}_{\text {angio }}$ in predicting IMR $\geq 40 \mathrm{U}$ in the whole cohort of 92 lesions

\begin{tabular}{llll}
\hline Variable & Post-pPCI IMR angio $<40 \mathrm{U}$ & Post-pPCI IMR $_{\text {angio }} \geq 40 \mathrm{U}$ & p-value \\
\hline Number of patients & $21(67.7)$ & $10(32.3)$ & \\
LVEDV $(\mathrm{ml})$ & $151(126-179)$ & $166(146-201)$ & 0.19 \\
LVESV(ml) & $80(56-108)$ & $83(67-121)$ & 0.67 \\
LVEF $(\%)$ & $49(40-54)$ & $50(41-57)$ & 0.70 \\
Infarct Size $(\mathrm{g})$ & $18(13-27)$ & $22(15-30)$ & 0.86 \\
Infarct Size $(\%)$ & $22(18.0-30)$ & $25(19-31)$ & 0.77 \\
MVO $>1.55 \%$ & $4(19)$ & $6(60)$ & 0.03
\end{tabular}

$\mathbf{A}$

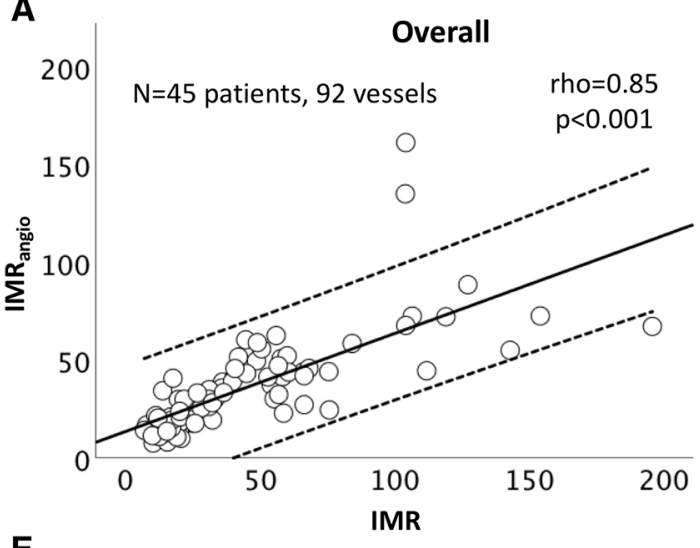

E

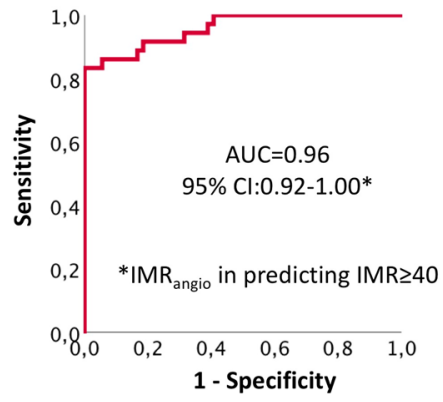

B



D

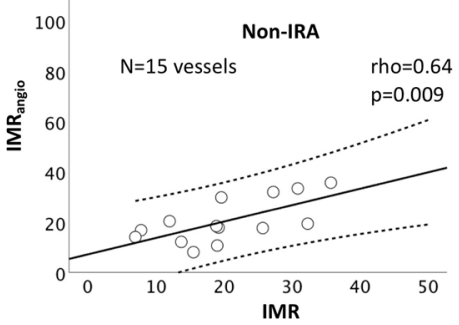

misclassification rate for response to stenting, with only 1 out of the 33 patients misclassified as "good responder" by $\mathrm{IMR}_{\text {angio }}$ and labelled as "poor responder" according to IMR variation post $\mathrm{pPCI}$.

\section{Correlation between IMR angio $_{\text {and MVO }}$}

CMR data are summarised in Table 2 and stratified accord-

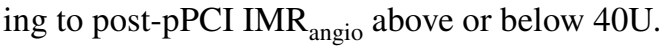

$\mathrm{IMR}_{\text {angio }}$ was significantly higher in patients with MVO> $1.55 \%$ (48.1U (29.3-68.9) vs 22.6U (13.7-39.0), $\mathrm{p}=0.005)$. Post-pPCI IMR ${ }_{\text {angio }}$ presented a satisfactory efficiency for prediction of $\mathrm{MVO}>1.55 \%(\mathrm{AUC}=0.81$ (CI95\% 0.65-0.97), p=0.006) (Fig. 6). At the pre-specified cut-off of $40 \mathrm{U}, \mathrm{IMR}_{\text {angio }}$ presented a $60.0 \%$ sensitivity, $80.0 \%$ specificity, $83.3 \%$ negative predictive value, $60.0 \%$ positive predictive value and $76.5 \%$ diagnostic accuracy).

\section{Discussion}

In the current study, we have derived and validated $\mathrm{IMR}_{\text {angio }}$ as a novel and pressure-wire-free index for the assessment of coronary microcirculation in STEMI patients. We have specifically observed that:

(1) IMR $_{\text {angio }}$ is significantly correlated with IMR both in the IRA and in the non-IRA of STEMI patients

(2) Both IMR and IMR ${ }_{\text {angio }}$ are significantly higher in the IRA than in the non-IRA

(3) A value of $40 \mathrm{U}$ appears the best threshold of IMR $\mathrm{Ingio}_{\text {ang }}$ to predict an abnormal IMR $(\geq 40 \mathrm{U})$ in STEMI patients


tained when these variables are measured before or after pPCI 
Fig. $4 \mathrm{IMR}_{\text {angio }}$ and IMR concordance. Bland-Altman plots summarise concordance between $\mathrm{IMR}_{\text {angio }}$ and IMR in the overall cohort of 92 lesions (a) and then split into IRA before stent implant (b), IRA after stent implant (c) and nonIRA (d)

A

Overall

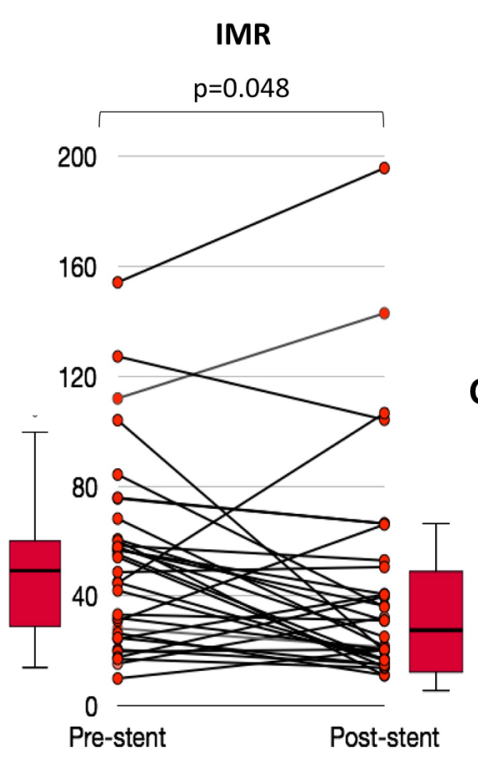

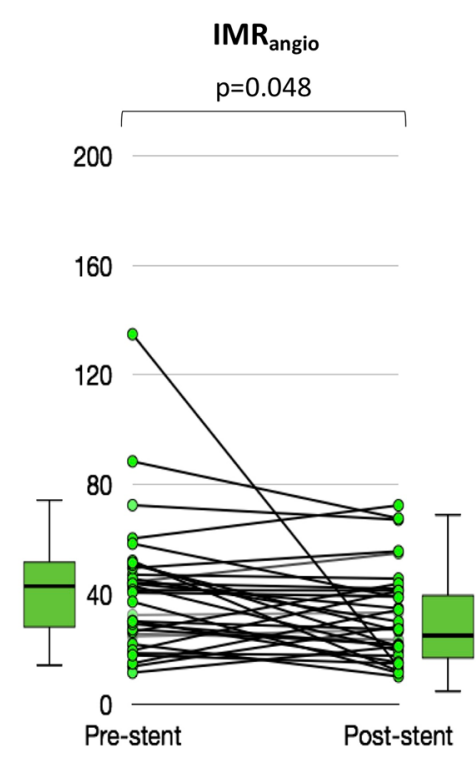
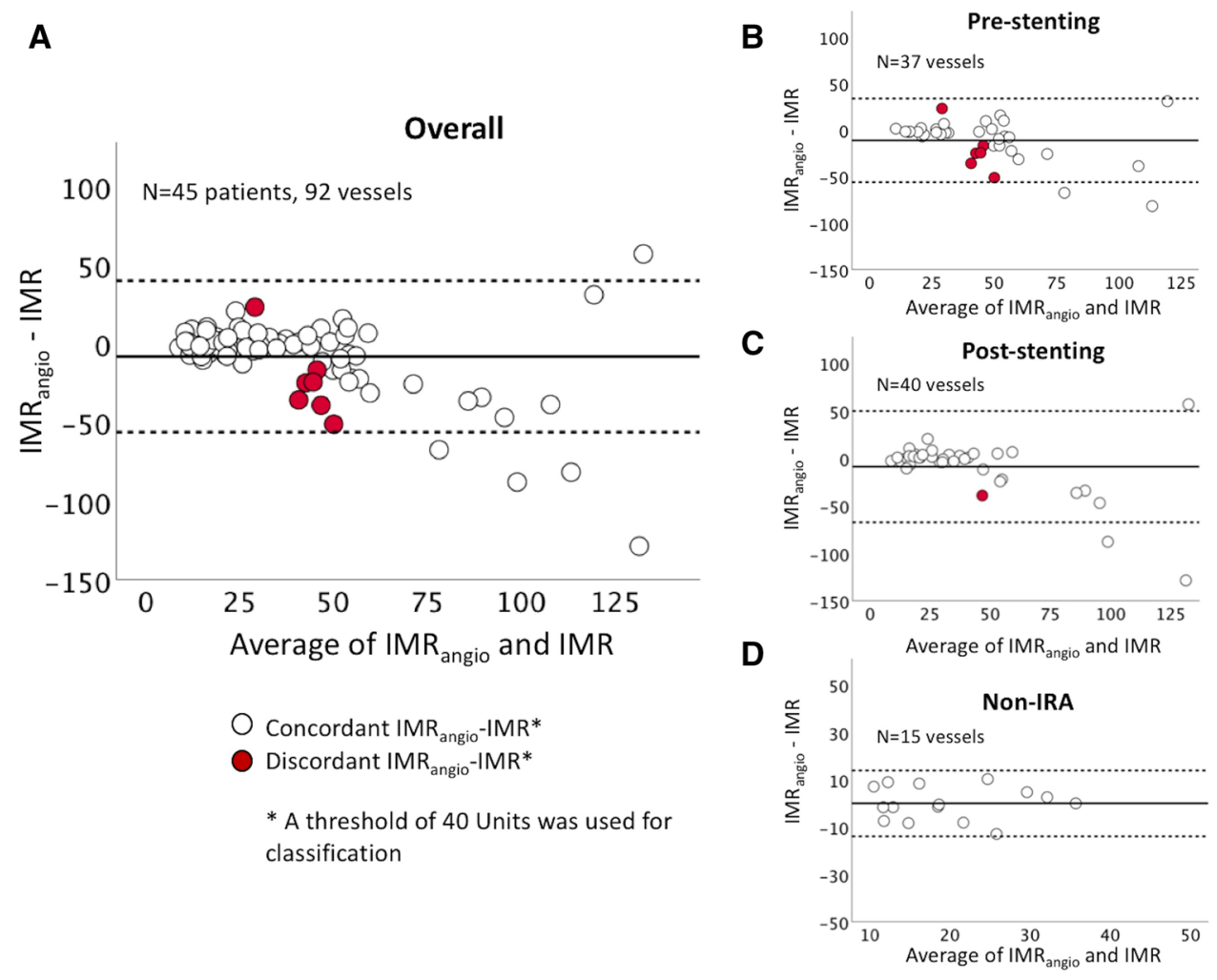

\section{B Good responders (post-pPCI IMR $<40 \mathrm{U}$ )}

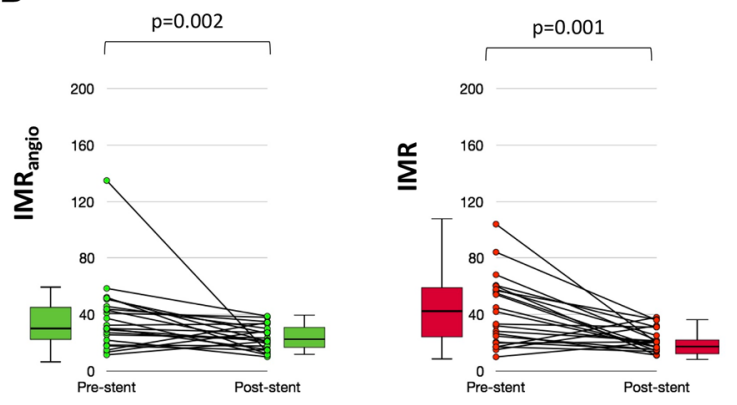

C Partial or poor responders (post-pPCI IMR $\geq \mathbf{4 0 ~ U}$ )

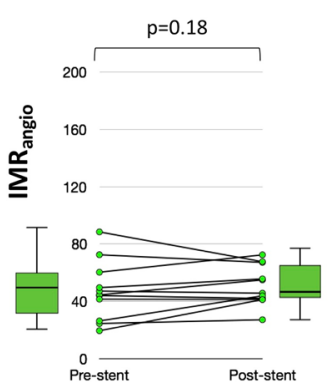

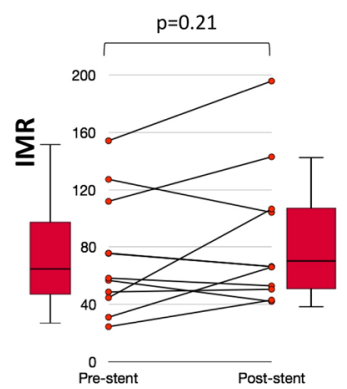

Fig. $5 \mathrm{IMR}_{\text {angio }}$ and IMR variations before and after stent implant. $\mathrm{IMR}_{\text {angio }}$ and IMR reduce after stent implantation (a). The change in $\mathrm{IMR}_{\text {angio }}$ consistently mirrored the change in IMR; the relationships persist when patients were divided into 'good' (b) or 'partial-poor' (c) responders to stent implant 


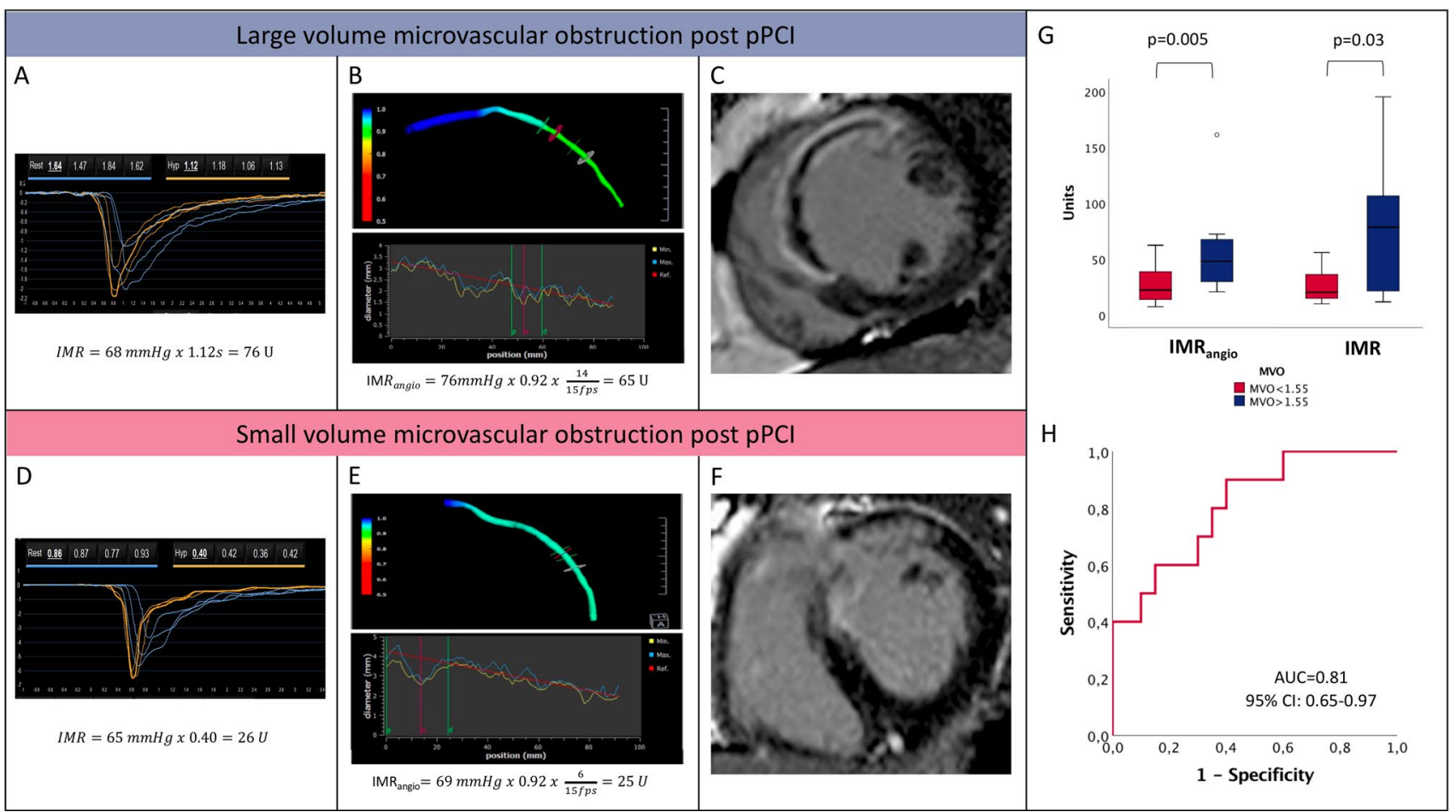

Fig. $6 \mathrm{IMR}_{\text {angio }}$ and MVO. The figure depicts two STEMI cases with IMR (a, d), IMR angio $(\mathbf{b}, \mathbf{e})$ assessment and corresponding short axis CMR images with presence (c) and absence (f) of MVO. The correlation between $\mathrm{IMR}_{\text {angio }}$ and IMR with the occurrence of clinically

(5) $\mathrm{IMR}_{\text {angio }}$ variation before and after pPCI mirrors the same variation that is observed in IMR

(6) $\mathrm{IMR}_{\text {angio }}$ measured at the end of pPCI is higher in patients with significant $\mathrm{MVO}$ and can predict the occurrence of significant MVO ( $>1.55 \%$ of left ventricle mass).

The availability and performance of pPCI have changed the prognosis for patients presenting with STEMI. However, up to $25-33 \%$ of STEMI patients will develop heart failure within five years of treatment, despite contemporary therapy [13]. Extensive coronary microvascular injury results in suboptimal reperfusion and this portends a larger infarct size and a higher risk of adverse remodelling [12]. Identifying, minimising and potentially reversing microvascular injury in STEMI is an unmet clinical need.

In addressing this challenge, assessing the status of coronary microvasculature within the catheter laboratory at the time of STEMI is pivotal since it has the potential to triage patients who might benefit from additional therapy. Early diagnosis/identification of "high risk' individuals is essential and IMR measurement using pressure-wire can offer a reasonable compromise between practicality and relevant MVO ( $>1.55 \%$ of left ventricle mass) is summarised by the box plots (g). Panel $\mathrm{H}$ depicts the ROC curve analysis of post-pPCI $\mathrm{IMR}_{\text {angio }}$ in predicting $\mathrm{MVO}>1.55$

diagnostic accuracy. However, measuring IMR increases procedural time, cost and has an intrinsic (but small) risk related to additional wire manipulation of the IRA (Fig. 7).

Within routine interventional practice, novel angiography-based indices are becoming available to address the limitations of pressure-wire-based measurement of FFR, using computational flow dynamics to model the coronary artery [8]. Amongst these indices, QFR is the one with the largest amount of data cumulated so far [9, 14]. QFR has been used extensively in routine practice to predict FFR, and its application to derive an angiography-based, pressure-wire-free parameter to depict the status of coronary microcirculation is now emerging [15].

This study demonstrates that IMR derived from QFR, labelled as $\mathrm{IMR}_{\text {angio }}$, can be measured in STEMI patients in the vast majority of cases in a standard catheter laboratory (95.7\% of lesions were successfully analysed for QFR and $\left.\mathrm{IMR}_{\text {angio }}\right)$. Comparisons showed a significant correlation between IMR and IMR ${ }_{\text {angio }}$, as confirmed by the ROC curve analysis. Previously, a post-pPCI IMR $\geq 40 \mathrm{U}$ has been shown to be prognostically relevant [3] and notably in our data, $\mathrm{IMR}_{\text {angio }}$ showed a similar upper cut-off of $40 \mathrm{U}$ to predict abnormal IMR. When applying this threshold of $40 \mathrm{U}$ 


\section{Central illustration. Potential clinical applications of IMR angio $_{\text {in STEMI }}$}

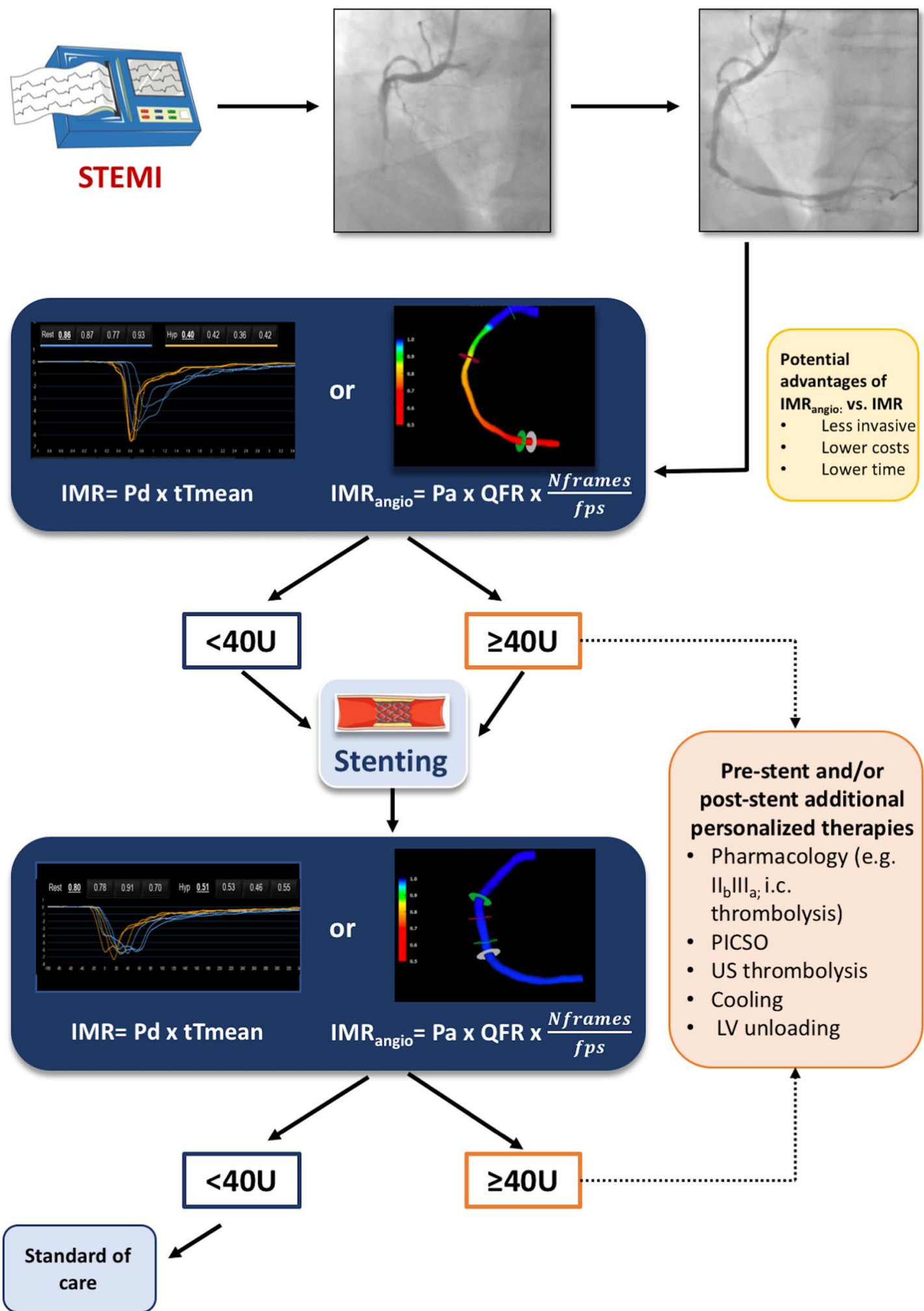

Fig. 7 Potential clinical implications of IMR $_{\text {angio }}$ in STEMI. IMR or IMR angio $_{\text {can }}$ be used to assess microvascular function in patients with STEMI undergoing pPCI before stenting (after flow restoration in the IRA) and at completion of pPCI 
for both IMR and IMR ${ }_{\text {angio }}$, they were concordant in $92 \%$ of cases, especially when the assessment was performed at the end of pPCI or in the non-IRA compared to assessment in the IRA before stent implant.

This result is further confirmed by the Bland-Altman analysis showing that $\mathrm{IMR}_{\text {angio }}$ and IMR are not numerically different for IMR values below $75 \mathrm{U}$. Above $75 \mathrm{U}, \mathrm{IMR}_{\text {angio }}$ can be instead either higher or lower than IMR. This observation emphasises that the absolute numerical values of the two variables are less related in cases of extreme (very high IMR) microvascular dysfunction (Fig. 4). This may reflect the previous suggestion that agreement between QFR and FFR is negatively affected by the presence of severe microvascular impairment [14]. However, even though the difference between IMR and IMR ${ }_{\text {angio }}$ values tends to widen with the severity of microvascular impairment, it remains a clinically meaningful concordance between the two measures. Indeed, both IMR and IMR ${ }_{\text {angio }}$ measurements are within the adverse range ( $>40 \mathrm{U})$ in cases of extreme microvascular dysfunction, with no cases of severely abnormal IMR presenting a normal $\mathrm{IMR}_{\text {angio }}$ and vice versa. Notably, the few cases of discordance were clustered around the threshold of 40U (Fig. 4).

Interestingly, in the subset of 15 patients with multivessel assessment, $\mathrm{IMR}_{\text {angio }}$ and IMR were correlated both in the IRA as in the non-IRA. Moreover, both IMR and IMR ${ }_{\text {angio }}$ appeared to be significantly higher in the IRA. This is in line with previous observations that microvascular impairment in the non-IRA, when present, is usually not severe and the observed values of IMR are not significantly different from those measured in patients with stable coronary artery disease 16].

In our study IMR and IMR $\mathrm{Ingio}_{\text {aio }}$ were measured at two time points (before and after stenting). We have previously described that, overall, IMR tends to improve after stenting, as a consequence of flow-mediated dilation of the microvascular bed 4]. However, a proportion of patients appear to experience a suboptimal response to stent implant, ending with a final IMR $\geq 40 \mathrm{U}$ as consequence of post-pPCI IMR increase or incomplete reduction below the desired threshold of $40 \mathrm{U} 4]$. The same trends were observed for $\mathrm{IMR}_{\text {angio }}$ in this study, with a similar rate of poor or partial responders to stenting when classification was based either on final $\mathrm{IMR}_{\text {angio }}$ or IMR.

Recently de Waha et al. have reported, in a pooled cohort of 1688 STEMI patients undergoing post-pPCI CMR, that MVO $>1.55 \%$ of left ventricle mass was associated with higher rates of mortality and heart failure at one year 12]. In our study, post-pPCI IMR ${ }_{\text {angio }}$ appeared significantly elevated in patients with evidence of clinically significant MVO ( $>1.55 \%$ of left ventricle mass) on CMR. This observation echoes that by McGeoch et al. who reported higher IMR values in STEMI patients with MVO 2].

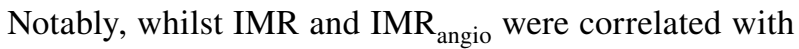
the presence of MVO, neither of them presented a strong correlation with the extent of MVO and infarct size. This discrepancy is consistent with previous studies 2]. Potential explanations include the difference in the timing of IMR/ $\mathrm{IMR}_{\text {angio }}$ measurement and CMR scanning and the fact that

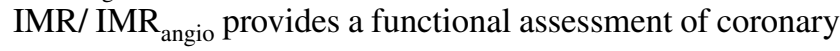
microcirculatory injury, whilst CMR an anatomical one 17].

\section{Limitations}

The relatively small sample size represents a limiting factor to keep into account when interpreting the results of the current study.

A second observation is that QFR and $\mathrm{IMR}_{\text {angio }}$ were both measured offline. This accounts for a small proportion of lesions that had to be discarded for IMR $_{\text {angio }}$ assessment because of suboptimal quality of angiographic views.

One of the advocated benefits of QFR in management of patients with stable coronary disease is that accuracy is maintained in predicting FFR, irrespective of the use of adenosine to achieve maximal vasodilation. The so called "contrast-QFR" represents an index that is pressure-wire and adenosine-free [8]. In our study, in order to replicate IMR, QFR (and thus $\mathrm{IMR}_{\text {angio }}$ ), was derived from angiographic views acquired at maximal hyperaemia achieved during intravenous adenosine infusion. In fact, the assessment of microvascular function in STEMI appears to be more reliable and consistent at maximal hyperaemia, since it is less prone to the heterogeneity of the same measurements obtained under resting conditions 18].

Whether $\mathrm{IMR}_{\text {angio }}$ might maintain the same diagnostic accuracy in predicting IMR and MVO also under non-hyperaemic conditions needs to be evaluated in future studies.

\section{Conclusions}

$\mathrm{IMR}_{\text {angio }}$ is a pressure-wire-free index with the potential to provide an easier and routine assessment of coronary microcirculation in the emergency setting of STEMI. Ultimately, even though further prospective validation is necessary in STEMI and across the spectrum of coronary artery disease, $\mathrm{IMR}_{\text {angio }}$ can be an easy, quick and cost-effective point-ofcare test for routine assessment of microvascular function in the catheter lab with the ultimate goal of facilitating 
prognostic stratification and early triage of ad-hoc/personalised therapies.

Funding Supported by British Heart Foundation (BHF; Grant $\mathrm{CH} / 16 / 1 / 32013$ ) BHF Centre of Research Excellence, Oxford (RG/13/1/30181) and the National Institute for Health Research (NIHR) Oxford Biomedical Research Centre.

\section{Compliance with ethical standards}

Conflict of interest All authors declare that they have no conflict of interest to disclose.

Ethical approval Prof Banning has received an unrestricted institutional research grant from Boston Scientific.

Open Access This article is licensed under a Creative Commons Attribution 4.0 International License, which permits use, sharing, adaptation, distribution and reproduction in any medium or format, as long as you give appropriate credit to the original author(s) and the source, provide a link to the Creative Commons licence, and indicate if changes were made. The images or other third party material in this article are included in the article's Creative Commons licence, unless indicated otherwise in a credit line to the material. If material is not included in the article's Creative Commons licence and your intended use is not permitted by statutory regulation or exceeds the permitted use, you will need to obtain permission directly from the copyright holder. To view a copy of this licence, visit http://creativecommons.org/licenses/by/4.0/.

\section{References}

1. Fearon WF, Balsam LB, Farouque HM, Caffarelli AD, Robbins RC, Fitzgerald PJ, Yock PG, Yeung AC (2003) Novel index for invasively assessing the coronary microcirculation. Circulation 107(25):3129-3132

2. McGeoch R, Watkins S, Berry C, Steedman T, Davie A, Byrne J, Hillis S, Lindsay M, Robb S, Dargie H, Oldroyd K (2010) The index of microcirculatory resistance measured acutely predicts the extent and severity of myocardial infarction in patients with ST-segment elevation myocardial infarction. JACC Cardiovasc Interv 3(7):715-722

3. Fearon WF, Low AF, Yong AS, McGeoch R, Berry C, Shah MG, Ho MY, Kim HS, Loh JP, Oldroyd KG (2013) Prognostic value of the Index of Microcirculatory Resistance measured after primary percutaneous coronary intervention. Circulation 127(24):2436-2441

4. De Maria GL, Cuculi F, Patel N, Dawkins S, Fahrni G, Kassimis G, Choudhury RP, Forfar JC, Prendergast BD, Channon KM, Kharbanda RK, Banning AP (2015) How does coronary stent implantation impact on the status of the microcirculation during primary percutaneous coronary intervention in patients with STelevation myocardial infarction? Eur Heart J 36(45):3165-3177

5. De Maria GL, Fahrni G, Alkhalil M, Cuculi F, Dawkins S, Wolfrum M, Choudhury RP, Forfar JC, Prendergast BD, Yetgin T, van Geuns RJ, Tebaldi M, Channon KM, Kharbanda RK, Rothwell PM, Valgimigli M, Banning AP (2016) A tool for predicting the outcome of reperfusion in ST-elevation myocardial infarction using age, thrombotic burden and index of microcirculatory resistance (ATI score). EuroIntervention 12(10):1223-1230
6. De Maria GL, Alkhalil M, Wolfrum M, Fahrni G, Borlotti A, Gaughran L, Dawkins S, Langrish JP, Lucking AJ, Choudhury RP, Porto I, Crea F, Dall'Armellina E, Channon KM, Kharbanda RK, Banning AP (2017) The ATI score (age-thrombus burdenindex of microcirculatory resistance) determined during primary percutaneous coronary intervention predicts final infarct size in patients with ST-elevation myocardial infarction: a cardiac magnetic resonance validation study. EuroIntervention 13(8):935-943

7. De Maria GL, Alkhalil M, Borlotti A, Wolfrum M, Gaughran L, Dall'Armellina E, Langrish JP, Lucking AJ, Choudhury RP, Kharbanda RK, Channon KM, Banning AP (2018) Index of microcirculatory resistance-guided therapy with pressure-controlled intermittent coronary sinus occlusion improves coronary microvascular function and reduces infarct size in patients with ST-elevation myocardial infarction: the Oxford Acute Myocardial Infarction-Pressure-Controlled Intermittent Coronary Sinus Occlusion study (OxAMI-PICSO study). EuroIntervention 14(3):e352-e359

8. Tu S, Westra J, Yang J, von Birgelen C, Ferrara A, Pellicano M, Nef H, Tebaldi M, Murasato Y, Lansky A, Barbato E, van der Heijden LC, Reiber JH, Holm NR, Wijns W (2016) FAVOR Pilot Trial Study group diagnostic accuracy of fast computational approaches to derive fractional flow reserve from diagnostic coronary angiography: the International Multicenter FAVOR Pilot Study. JACC Cardiovasc Interv 9(19):2024-2035

9. Westra J, Andersen BK, Campo G, Matsuo H, Koltowski L, Eftekhari A, Liu T, Di Serafino L, Di Girolamo D, Escaned J, Nef H, Naber C, Barbierato M, Tu S, Neghabat O, Madsen M, Tebaldi M, Tanigaki T, Kochman J, Somi S, Esposito G, Mercone G, Mejia-Renteria H, Ronco F, Bøtker HE, Wijns W, Christiansen EH, Holm NR (2018) Diagnostic performance of in-procedure angiography-derived quantitative flow reserve compared to pressure-derived fractional flow reserve: the FAVOR II Europe-Japan Study. J Am Heart Assoc. https://doi.org/10.1161/ JAHA.118.009603

10. Cuculi F, De Maria GL, Meier P, Dall'Armellina E, de Caterina AR, Channon KM, Prendergast BD, Choudhury RP, Forfar JC, Kharbanda RK, Banning AP (2014) Impact of microvascular obstruction on the assessment of coronary flow reserve, index of microcirculatory resistance, and fractional flow reserve after ST-segment elevation myocardial infarction. J Am Coll Cardiol 64(18):1894-1904

11. Borlotti A, Jerosch-Herold M, Liu D, Viliani D, Bracco A, Alkhalil M, De Maria GL, OxAMI Study Investigators, Channon KM, Banning AP, Choudhury RP, Neubauer S, Kharbanda RK, Dall'Armellina E (2019) Acute microvascular impairment post-reperfused STEMI is reversible and has additional clinical predictive value: a CMR OxAMI Study. JACC Cardiovasc Imaging 12(9):1783-1793

12. de Waha S, Patel MR, Granger CB, Ohman EM, Maehara A, Eitel I, Ben-Yehuda O, Jenkins P, Thiele H, Stone GW (2017) Relationship between microvascular obstruction and adverse events following primary percutaneous coronary intervention for STsegment elevation myocardial infarction: an individual patient data pooled analysis from seven randomized trials. Eur Heart $\mathbf{J}$ 38(47):3502-3510

13. Ezekowitz JA, Kaul P, Bakal JA, Armstrong PW, Welsh RC, McAlister FA (2009) Declining in-hospital mortality and increasing heart failure incidence in elderly patients with first myocardial infarction. J Am Coll Cardiol 53(1):13-20

14. Mejía-Rentería H, Lee JM, Lauri F, van der Hoeven NW, de Waard GA, Macaya F, Pérez-Vizcayno MJ, Gonzalo N, JiménezQuevedo P, Nombela-Franco L, Salinas P, Núñez-Gil I, Del Trigo M, Goto S, Lee HJ, Liontou C, Fernández-Ortiz A, Macaya C, van Royen N, Koo BK, Escaned J (2018) Influence of microcirculatory dysfunction on angiography-based functional assessment of coronary stenoses. JACC Cardiovasc Interv 11(8):741-753 
15. Sheng X, Qiao Z, Ge H, Sun J, He J, Li Z, Ding S, Pu J (2020) Novel application of quantitative flow ratio for predicting microvascular dysfunction after ST-elevation-elevation myocardial infarction. Catheter Cardiovasc Interv. https://doi.org/10.1002/ ccd. 28718

16. Choi KH, Lee JM, Kim HK, Kim J, Park J, Hwang D, Rhee TM, Park TK, Yang JH, Song YB, Shin ES, Nam CW, Doh JH, Hahn JY, Choi JH, Choi SH, Koo BK, Gwon HC (2018) Fractional flow reserve and instantaneous wave-free ratio for nonculprit stenosis in patients with acute myocardial infarction. JACC Cardiovasc Interv 11(18):1848-1958

17. De Maria GL, Alkhalil M, Wolfrum M, Fahrni G, Borlotti A, Gaughran L, Dawkins S, Langrish JP, Lucking AJ, Choudhury RP, Porto I, Crea F, Dall'Armellina E, Channon KM, Kharbanda RK, Banning AP (2019) Index of microcirculatory resistance as a tool to characterize microvascular obstruction and to predict infarct size regression in patients with STEMI undergoing primary PCI. JACC Cardiovasc Imaging 12(5):837-848

18. Mejia-Renteria H, Lee JM, van der Hoeven NW, Gonzalo N, Jiménez-Quevedo P, Nombela-Franco L, Nuñez-Gil IJ, Salinas P, Del Trigo M, Cerrato E, van Royen N, Knaapen P, Koo BK, Macaya C, Fernández-Ortiz A, Escaned J (2019) Coronary microcirculation downstream non-infarct-related arteries in the subacute phase of myocardial infarction: implication for physiology-guided revascularization. J Am Heart Assoc 8(9):e011534. https://doi. org/10.1161/JAHA.118.011534

Publisher's Note Springer Nature remains neutral with regard to jurisdictional claims in published maps and institutional affiliations. 